\title{
Point-of-care ultrasonography in critical care medicine: a one way directional road
}

\author{
Pablo Blanco $^{1} \cdot$ Francisco Miralles Aguiar $^{2} \cdot$ Alfredo Vallejo $^{3}$
}

Received: 18 December 2015/Accepted: 22 December 2015/Published online: 18 January 2016

(C) Società Italiana di Ultrasonologia in Medicina e Biologia (SIUMB) 2016

Dear editor,

We would like to call attention upon the fact that currently there are two paths or modi operandi that can be recognized when working with critical care patients: the traditional paradigm and the ultrasound-supported paradigm [1]. The first consists in using ultrasonography (US) "inconstantly" in sick patients, in other words, in an oncall manner and performed by specialists (e.g., radiologists and/or echocardiographers). By contrast, the US-supported paradigm consists in using US by intensivists at the patientś bedside with the purpose to add valuable information to further support, refute or change a clinical diagnostic hypothesis and also to assist in common interventional procedures. In the latter paradigm, the US is extensively available and specialistś consulting is seldom required.

In terms of the paradigm that is being currently used, it seems that US use is growing up in critical care settings, but, still, it does not win the fight against its former competitor. Some numbers allow us to affirm this concept. A recent multicenter study involving 142 adult intensive care unit (ICU) patients of France, Belgium and Switzerland [2], showed that point-of-care US (POCUS) was used in approximately one-third (36\%) of the patient population/day, predominantly for diagnostic purposes in $87 \%$ of

Pablo Blanco

ohtusabes@gmail.com

1 Intensive Care Unit, Hospital "Dr. Emilio Ferreyra”, 4801, 59 St., 7630 Necochea, Argentina

2 Intensive Care Unit, Hospital General "Santa María del Puerto”, 11500 El Puerto de Santa María, Cádiz, Spain

3 Hospital de Niños "Dr. Orlando Allasia”, 3000 Santa Fe, Argentina the cases, whereas for interventional guidance was used in only $13 \%$ of indications.

Reasoning about these findings, it is intuitive asking how were managed the remaining $64 \%$ (the most) who did not receive an US-based approach.

It is supposed that deliberate US use is not a routine practice in intensive care settings, but according to diagnostic and procedural guidance capabilities of this noninvasive and indolent diagnostic imaging method, why not to extend POCUS to a $100 \%$ of the patient population/day is a logical question that could naturally arise.

Limitations for using POCUS are probably multiple, ranging from the common physicianś believe that US is a merely "operator-dependent" method, passing through the unproven fact that US has never demonstrated survival benefits to critically ill patients, up to the scarce monetary resources to purchase and maintain an ultrasound machine, being the last specially relevant in developing countries.

It seems that a lot of reasons for not using POCUS exist; however, there is still an important amount of uncertainty from practitioners about using US, mostly related to the skepticism related to a technique which, at first glance, does not belong to the scope of intensivists.

We encourage intensivists to change their work path from the traditional paradigm to the US-supported paradigm if they have not already done so. Benefits are clearly demonstrated for patients and also physicians and nurses working in ICU.

On the contrary, changing from the US-supported paradigm to the other one is not possible due to the fact that POCUS seems to be a one-way directional road.

Acknowledgments The authors would like to thank Mrs. Celeste Bruno for the language guidance. 


\section{Compliance with ethical standards}

Conflict of interest Authors have no conflict of interest to disclose.

Human and animal studies This article does not contain any studies with human participants or animals performed by any of the authors.

Informed consent For this type of study formal consent is not required.

\section{References}

1. Blanco P (2015) A traditional paradigm vs. an ultrasoundsupported paradigm in emergency and critical care medicine: a crisis of the mind is needed. J Emerg Med 49(2):e63-e64
2. Zieleskiewicz L, Muller L, Lakhal K, Meresse Z, Arbelot C, Bertrand PM, Bouhemad B, Cholley B, Demory D, Duperret S, Duranteau J, Guervilly C, Hammad E, Ichai C, Jaber S, Langeron O, Lefrant JY, Mahjoub Y, Maury E, Meaudre E, Michel F, Muller M, Nafati C, Perbet S, Quintard H, Riu B, Vigne C, Chaumoitre K, Antonini F, Allaouchiche B, Martin C, Constantin JM, De Backer D, Leone M (2015) Point-of-care ultrasound in intensive care units: assessment of 1073 procedures in a multicentric, prospective, observational study. Intensive Care Med 41(9):1638-1647 